\title{
Network Analysis Reveals Seasonal Patterns of Bacterial Community Networks in Lake Taihu under Aquaculture Conditions
}

\author{
Yuqing Lin ${ }^{1}$, Dayong Zhao ${ }^{1,2, *}$, Jin Zeng ${ }^{3}$, Xinyi Cao ${ }^{1,3}$ and Congcong Jiao ${ }^{1,3}$ (1) \\ 1 State Key Laboratory of Hydrology-Water Resources and Hydraulic Engineering, Joint International \\ Research Laboratory of Global Change and Water Cycle, Hohai University, Nanjing 210098, China \\ 2 Experimental Teaching Center of Water Resources, Hohai University, Nanjing 210098, China \\ 3 State Key Laboratory of Lake Science and Environment, Nanjing Institute of Geography and Limnology, \\ Chinese Academy of Sciences, Nanjing 210008, China \\ * Correspondence: dyzhao@hhu.edu.cn; Tel.: +86-25-8378-7891
}

Received: 6 July 2019; Accepted: 5 September 2019; Published: 8 September 2019

\begin{abstract}
Bacterial communities play essential roles in multiple ecological processes, such as primary production and nutrient recycling in aquatic systems. However, although the composition, diversity and function of bacterial communities have been well studied, little is known about the interactions and co-occurrence characteristics of these communities, let alone their seasonal patterns. To investigate the seasonal variations of bacterial community interactions, we collected water samples from four seasons in Lake Taihu and applied network analysis to reveal bacterial community interactions. Bacterial community networks were non-random in structure, and interactions among bacterial taxa in the networks varied markedly in different seasons. The autumnal bacterial network was the largest and most complex among obtained networks, whereas the spring correlation network was the simplest, having no module hubs or connectors. The important species of the networks were the dominant bacterial phyla/classes (e.g., Alphaproteobacteria and Bacteroidetes), although their relative abundance varied among seasons. The relationships between species and measured environmental variables changed over seasons; fewer environmental factors were correlated with bacterial species in the spring bacterial network, while we observed a greater number of species-environment correlations in the winter network. Our study highlights the seasonal differences in bacterial community interactions and expands our understanding of freshwater microbial ecology in systems affected by aquaculture.
\end{abstract}

Keywords: network analysis; bacterial community interactions; seasonal variation; aquaculture; Lake Taihu

\section{Introduction}

China is the world's largest producer of aquatic animals, its aquacultural output, which represents approximately $60 \%$ of global production [1]. Lake Taihu is a representative site of freshwater aquaculture within China. Aquaculture contributed $45 \%$ of the agricultural gross domestic product for the Taihu Lake watershed [2], and the majority of Eastern Lake Taihu has been covered with aquaculture nets to expand the area of aquaculture since 2006 [3]. Owing to the rapid development of aquaculture in Eastern Lake Taihu, large quantities of waste materials (e.g., feces, residual feed and antibiotics) have degraded water quality [4] and influenced the biogeochemical processes mediated by microorganism [5]. Meanwhile, antibiotic pollution generated further influences the distribution of antibiotic-resistant bacteria [6]. 
Bacterial communities in aquatic systems play essential roles in the ecological processes of water bodies, including in primary production and nutrient recycling $[7,8]$. Understanding interactions (e.g., competition, predation, mutualism and parasitism) between bacterial taxa [9] and isolating the relationships between bacterial communities and environmental forcing factors (e.g., seasonality [10-12] and nutrient concentrations $[13,14])$ in freshwater ecosystems is an essential theme in microbial ecology [15]. Numerous studies have been performed to evaluate the composition and diversity of bacterial communities, which have shown that microorganism assemblages are seasonally dependent [16-19]. However, most of these studies were centered on the variation of diversity or composition of bacterial communities, whereas the complex interactions between bacterial taxa and the seasonal co-occurrence/co-exclusion patterns of lacustrine bacterial communities remain largely unknown. Furthermore, co-occurrence relationships among bacterial taxa across seasons may provide valuable insights into the ecological mechanism underlying the response of microbes to environmental change [20].

The rapid development of high-throughput sequencing technologies has favored network analysis and the exploration of complex correlations of bacterial communities [21-23]. In an ecological network, each object (species or gene) is described as a node, and the pairwise relationship is described as an edge $[24,25]$. A series of network topological parameters can be used to characterize properties of the constructed network, such as modularity, clustering coefficient, network diameter, average path length, graph density and average degree. Moreover, although some co-occurring bacteria may not interact directly with each other, network analysis could provide effective insight into potential interactions among bacteria taxa owing to the available network analysis is correlation-based [9]. In the present study, 32 aquaculture-influenced water samples from Eastern Lake Taihu across four seasons (i.e., spring, summer, autumn and winter) to investigate the interactions between bacterial taxa and apply network analysis elucidate the relationships between bacterial interactions and environmental variables. The following scientific questions were addressed: (i) Do the interactions among bacterial taxa vary remarkably in different seasonal bacterial groups affected by aquaculture activities? (ii) Do individual Operational Taxonomic Units (OTUs) play different topological roles in the seasonal bacterial community networks? (iii) Do the relationships between bacterial species and environmental variables change over seasons?

\section{Materials and Methods}

\subsection{Sample Collection and Measurement of Physicochemical Variables}

We collected 32 water samples from a pair of zones in Eastern Lake Taihu, China (i.e., grass-crab zone (GC) and grass-crab-fish zone (GCF)) in four seasons (i.e., autumn, October 2015; winter, January 2016; spring, April 2016; summer, August 2016 - eight water samples were collected during each season). Both zones have been subjected to long-term aquaculture. Details of the location and the distribution of the sampling sites were shown in Figure 1. We collected water samples at $0.5 \mathrm{~m}$ below the surface water. We measured physicochemical properties of water samples (including water temperature (T), $\mathrm{pH}$ and dissolved oxygen (DO)) in situ using a water quality sonde (YSI 6600, Yellow Springs, OH, USA). Other environmental variables such as chlorophyll-a (Chla), total nitrogen (TN), total phosphorus (TP), ammonia nitrogen $\left(\mathrm{NH}_{4}{ }^{+}-\mathrm{N}\right)$, nitrate nitrogen $\left(\mathrm{NO}_{3}{ }^{-} \mathrm{N}\right)$ and nitrite nitrogen $\left(\mathrm{NO}_{2}{ }^{-} \mathrm{N}\right)$, were measured in the laboratory following previous methods [14]. Dissolved organic carbon (DOC) and water transparency were examined as described in a previous study [26].

\subsection{DNA Extraction, Polymerase Chain Reaction (PCR) Amplification and Illumina Sequencing}

The methods of DNA extraction, amplification and Illumina MiSeq sequencing followed those of a recent study [26]. The raw sequencing data were deposited in the National Center for Biotechnology Information (NCBI) Sequence Read Archive (SRA) database (accession number: SRP155498). 


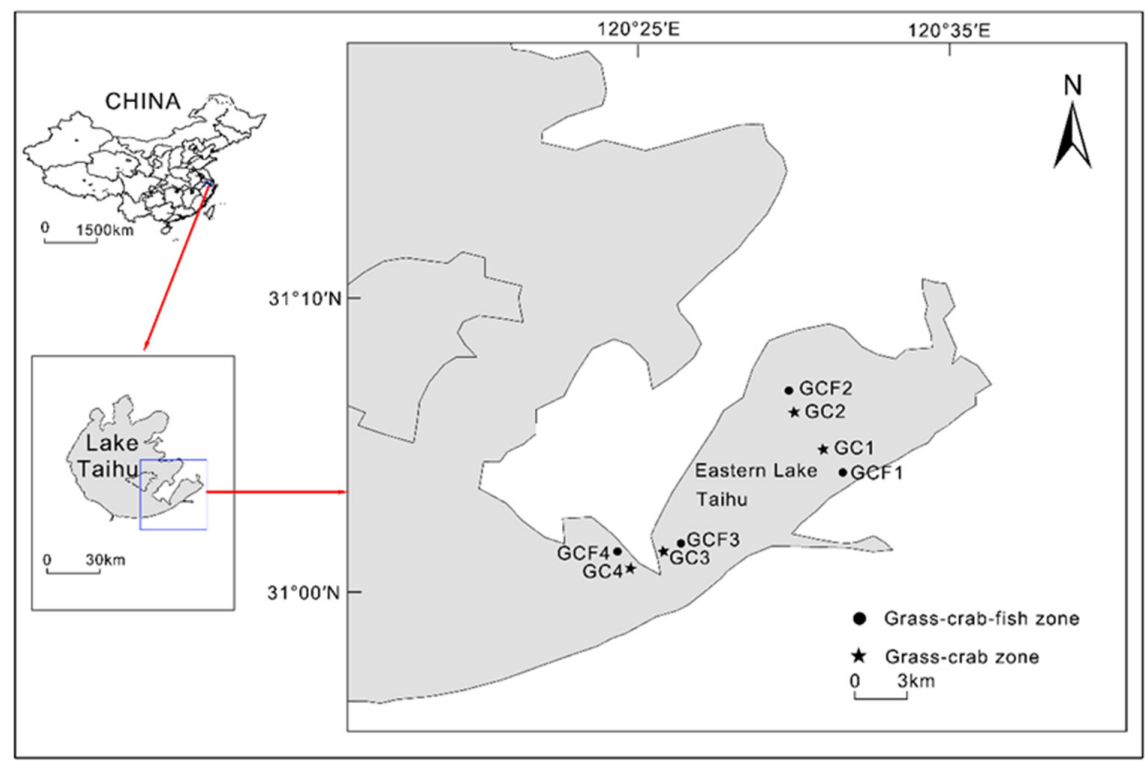

Figure 1. Location map of sampling sites in Eastern Lake Taihu. GC, grass-crab zone; GCF, grass-crab-fish zone.

\subsection{Sequence Data Processing and Statistical Analysis}

Raw reads of the bacterial 16SrRNA gene were processed using Quantitative Insights Into Microbial Ecology (QIIME) v.1.9 (http://qiime.org) [27]. We discarded any reads had a quality criterion with a quality score $<25$ or a sequence length shorter than $100 \mathrm{bp}$ for $16 \mathrm{~S}$ amplicon reads using Trimmomatic [28]. Only those trimmed sequences that had overlapped lengths longer than $10 \mathrm{bp}$ and a mismatch density lower than 0.25 were jointed using FLASH (http://ccb.jhu.edu/software/FLASH/) [29]. We identified chimeras and then used UCHIME in the de novo mode to remove them [30]. After the pre-processing of the obtained sequences, 979255 quality sequences were obtained for the $16 \mathrm{~S}$ rRNA. Operating taxonomic units (OTUs) were clustered at $97 \%$ sequence similarity by using the UCLUST (pick_otus.py) [31] in QIIME, and we selected representative sequences by using VSEARCH (pick_rep_set.py) [32]. The ribosomal database project (RDP) classifier assigned taxonomic classifications and obtained taxonomic information based on $80 \%$ bootstrap cut-off threshold [33,34]. We aligned and filtered representative sequences using the Python Nearest Alignment Space Termination (PyNAST) algorithm [35] against a bacterial SILVA v.132 database of 16S rRNA genes [36], and the phylogenetic tree was constructed in FastTree [37]. The final OTU table was generated based on the clustering results and we excluded suspicious OTUs (sequence number $<2$ ) that occurred in only one sample [38]. With the minimum numbers of sequences in one sample being 22,136 for the $16 \mathrm{~S}$ rRNA gene, subsampled sequences were used for subsequently all OTU-based network analyses. We analyzed relative abundance of bacteria taxa and diversity of bacterial communities based on the final OTU table, following a recent study [27].

\subsection{Seasonal Network Construction and Characterization}

All water samples were divided into four groups (i.e., spring, summer, autumn and winter). Only OTUs that appeared in at least six samples in each group were selected to improve the network reliability [12,39]. The relative proportion of sequence numbers helped in the subsequent correlation analysis, as the sequence numbers of obtained individual OTUs obtained varied markedly among the different samples [40]. In each group, we constructed a pair of correlation matrices based on the relative abundance of the OTUs of each sample. We used the 'Hmsic' package in R statistical software (v.3.3.1) [41] to calculate both the correlation ( $R$ matrix) and significance matrices ( $P$ matrix) by computing all possible pairwise Spearman's correlations among all OTUs in each group. We maintained only strong correlations (Spearman's rank correlation coefficient, $r>0.9$ (or $r<-0.9)$ ) and statistically 
significant ( $p \leq 0.001$ ) results to construct the networks $[9,12,42]$. The node connectivity (i.e., number of edges connected to a node) was plotted against the probability $P(k)$ that a node would have that degree in the network. We used three methods (i.e., power law, exponential law and truncated law) to fit the degree distribution of the four seasonal networks [43].

The constructed correlation matrix was transformed into a Cytoscape dataset in $\mathrm{R}$ and we then generated topological networks. Network visualization was completed in Cytoscape v.3.6.1 (https://cytoscape.org) [44,45]. Other important information, including nodes (OTUs), edges (positive or negative interactions), modules and weights, was also imported into Cytoscape. We divided each seasonal network into modules by fast greedy modularity optimization [46]. The topological characteristics of seasonal networks were described by modularity, clustering coefficient, average path length, network diameter, average degree and graph density. We calculated these parameters using the 'igraph' package in R. We used these same parameters to compare our observed networks with random networks [47]. The network parameters of each random network were the average and standard deviation of 1000 random networks. Significant differences between the topological indices of the observed and random networks for each group were determined using a Z-test in R [12].

\subsection{Topological Roles of Individual Nodes}

We used a pair of parameters (i.e., within-module connectivity (Zi) and connectivity among modules (Pi)) to describe the topological roles of individual nodes (OTUs) [48]. The distribution of nodes in the networks was visualized in Sigmaplot (v.12.5). Nodes could be separated into four subcategories based on the values of $\mathrm{Zi}$ and $\mathrm{Pi}$ : (i) peripheral nodes ( $\mathrm{Zi} \leq 2.5, \mathrm{Pi} \leq 0.62)$; (ii) connectors ( $\mathrm{Zi} \leq 2.5, \mathrm{Pi}>0.62)$; (iii) module hubs $(\mathrm{Zi}>2.5, \mathrm{Pi} \leq 0.62)$; (iv) network hubs $(\mathrm{Zi}>2.5, \mathrm{Pi}>0.62)$ [41].

\subsection{Relationships between Bacterial Networks and Environmental Variables}

Environmental variables were integrated into the seasonal networks to explore the relationships between the distribution of nodes (species) and the network and environmental variables. To improve the reliability of species-environment networks, we considered only statistically significant $(p<0.01)$ and robust $(r \geq 0.6$ or $r \leq-0.6)$ correlations. We visualized the species-environment networks using Cytoscape v.3.6.1 [45].

\section{Results}

\subsection{Network Structure of Bacterial Communities in Different Seasons}

Although we constructed four seasonal networks based on species-species correlations using identical thresholds, we found marked differences in the network size of the bacterial communities. Specifically, the largest network (905 nodes and 1696 edges) and the smallest network (243 nodes and 225 edges) occurred in autumn and spring, respectively, while the summer and winter networks were similar and moderate in size (Table 1 and Figure 2). Additionally, we observed remarkable differences of bacterial community alpha diversity, with the highest values in autumn and lowest in spring (Figure S1). Furthermore, significant difference of beta diversity of bacterial community was found in different seasons (Analysis of Variance (ANOVA): $p<0.001, r=0.4933$; Figure S2). Topological indices, modularity and the clustering coefficient for the 4 seasonal networks were greater $(p<0.001)$ than those of random networks based on Z-tests (Table 1). Moreover, the average path length and the network diameter of the spring and autumn networks were, respectively, lower and higher than those of the random networks; however, average path length and network diameter of the summer and winter networks were more similar to those of random networks (Table 1). The degrees of distribution of the 4 constructed networks had a best fit with the truncated power law, coefficients of $0.9955,0.9984$ and 0.9936 for the spring, summer and autumn groups, respectively; the winter network had a best fit by exponential law, with a coefficient of 0.331 (Figure S3). 
The five phyla/classes including Actinobacteria, Alphaproteobacteria, Bacteroidetes, Betaproteobacteria and Gammaproteobacteria dominated (having a percentage of nodes $>5 \%$ ) in the four bacterial networks (Figure 3 and Table S1). These bacterial phyla/classes varied remarkably in different seasons (Figure 3). Other phyla (e.g., Aminicenantes, Cloacimonetes and Lentisphaerae) only appeared in a single season (Table S1). Among the five dominant phyla/classes, Bacteroidetes maintained a relatively high abundance between seasons. Additionally, Cyanobacteria were the most abundant in the summer (Figure 3). Moreover, we observed the relative abundance of most phyla/classes varied markedly across seasons (Figure S4).

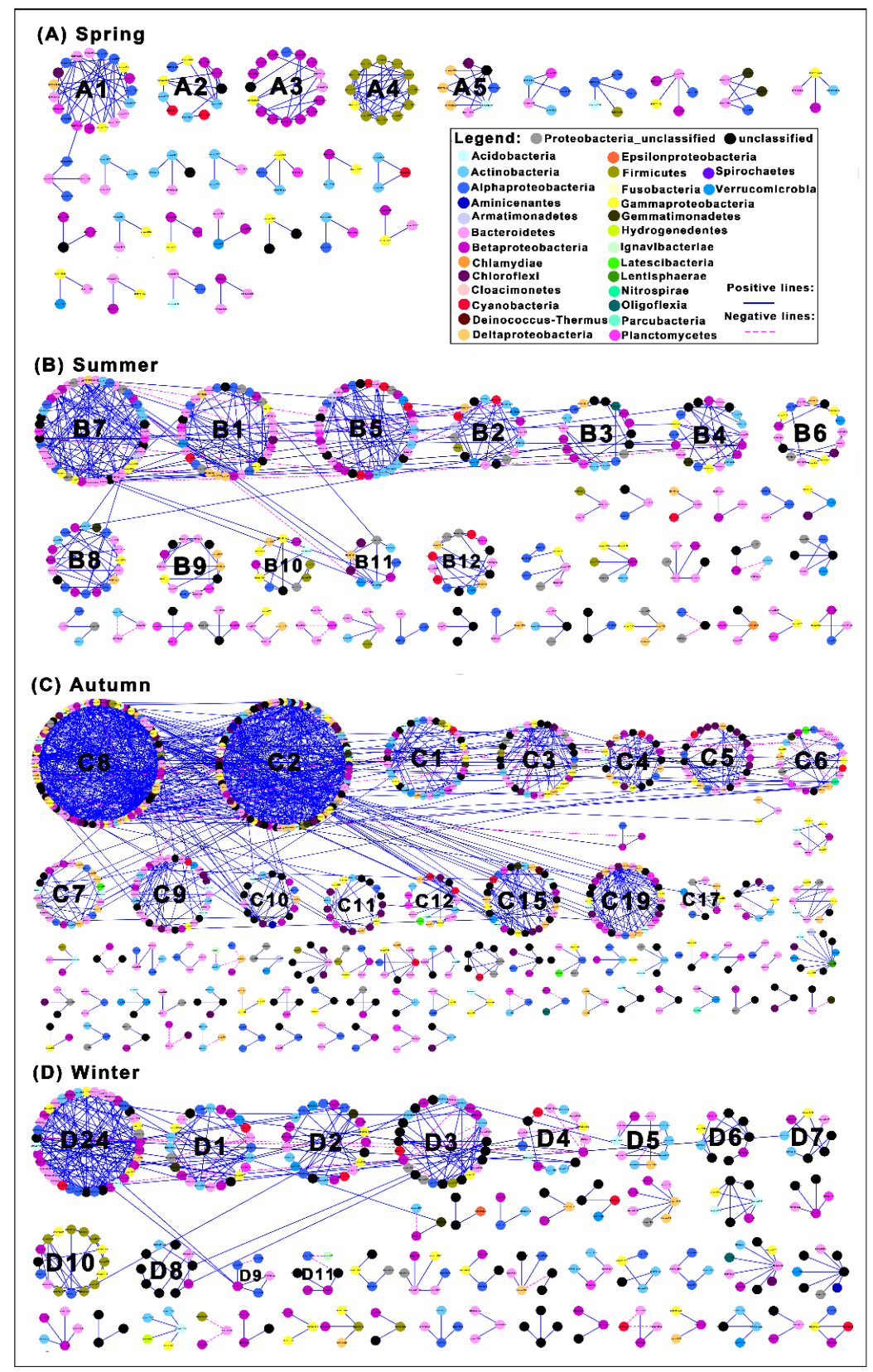

Figure 2. Species-species association network divided by modules for the spring (A), summer (B), autumn (C) and winter (D) bacterial communities. Only correlations between species that were statistically significant $(p<0.001)$ and strong $(r>0.9$ or $r<-0.9)$ are shown by the solid blue lines (positive correlations) and dotted pink lines (negative correlations), respectively. Correlations solely between pairs of operating taxonomic units (OTUs) are not shown. Different bacterial phyla/classes are represented by different colors, and the number on each node refers to the ID number of each OTU. 
Table 1. Topological properties of the empirical networks of bacterial communities and their associated random networks in different seasons.

\begin{tabular}{|c|c|c|c|c|c|c|c|c|c|c|c|c|c|}
\hline \multirow{3}{*}{ Groups } & \multirow{3}{*}{$\begin{array}{l}\text { Number } \\
\text { of nodes }\end{array}$} & \multicolumn{6}{|c|}{ Empirical Network } & \multicolumn{6}{|c|}{ Random Network } \\
\hline & & \multicolumn{2}{|c|}{ Number of edges } & \multirow[t]{2}{*}{ Modularity } & \multirow[t]{2}{*}{$\begin{array}{l}\text { Clustering } \\
\text { coefficient }\end{array}$} & \multirow[t]{2}{*}{$\begin{array}{l}\text { Average } \\
\text { path } \\
\text { length }\end{array}$} & \multirow[t]{2}{*}{$\begin{array}{l}\text { Network } \\
\text { diameter }\end{array}$} & \multirow[t]{2}{*}{$\begin{array}{c}\text { Average } \\
\text { degree }\end{array}$} & \multirow[t]{2}{*}{$\begin{array}{l}\text { Graph } \\
\text { density }\end{array}$} & \multirow[t]{2}{*}{$\begin{array}{l}\text { Modularity } \\
\text { (SD) }\end{array}$} & \multirow[t]{2}{*}{$\begin{array}{l}\text { Clustering } \\
\text { coefficient } \\
\text { (SD) }\end{array}$} & \multirow[t]{2}{*}{$\begin{array}{l}\text { Average } \\
\text { path length } \\
\text { (SD) }\end{array}$} & \multirow[t]{2}{*}{$\begin{array}{l}\text { Network } \\
\text { diameter } \\
\text { (SD) }\end{array}$} \\
\hline & & Positive & Negative & & & & & & & & & & \\
\hline Spring & 243 & 225 & 0 & $0.931^{\mathrm{a}}$ & $0.193^{\mathrm{a}}$ & $2.492^{\mathrm{a}}$ & $8^{\mathrm{a}}$ & 1.852 & 0.008 & $0.773(0.016)$ & $0.007(0.009)$ & $7.488(0.573)$ & $\begin{array}{l}18.536 \\
(2.400)\end{array}$ \\
\hline Summer & 482 & 521 & 64 & $0.852^{a}$ & $0.251^{\mathrm{a}}$ & $6.445^{\mathrm{b}}$ & $17^{b}$ & 2.427 & 0.005 & $0.699(0.009)$ & $0.005(0.004)$ & $6.604(0.166)$ & $\begin{array}{l}15.627 \\
(1.365)\end{array}$ \\
\hline Autumn & 905 & 1594 & 102 & $0.739^{a}$ & $0.177^{a}$ & $6.994^{\mathrm{a}}$ & $22^{a}$ & 3.748 & 0.004 & $0.540(0.004)$ & $0.004(0.002)$ & $5.240(0.033)$ & $\begin{array}{l}11.322 \\
(0.792)\end{array}$ \\
\hline Winter & 435 & 440 & 68 & $0.851^{a}$ & $0.196^{\mathrm{a}}$ & $6.723^{\mathrm{b}}$ & $17^{b}$ & 2.320 & 0.005 & $0.714(0.010)$ & $0.005(0.004)$ & $6.759(0.193)$ & $\begin{array}{l}16.230 \\
(1.530)\end{array}$ \\
\hline
\end{tabular}

SD, standard deviation. ${ }^{a}$ Significant difference $(p<0.001)$ between the empirical network and the random network. ${ }^{\text {b }}$ Significant difference $(p>0.05)$ between the empirical network and the random network. 


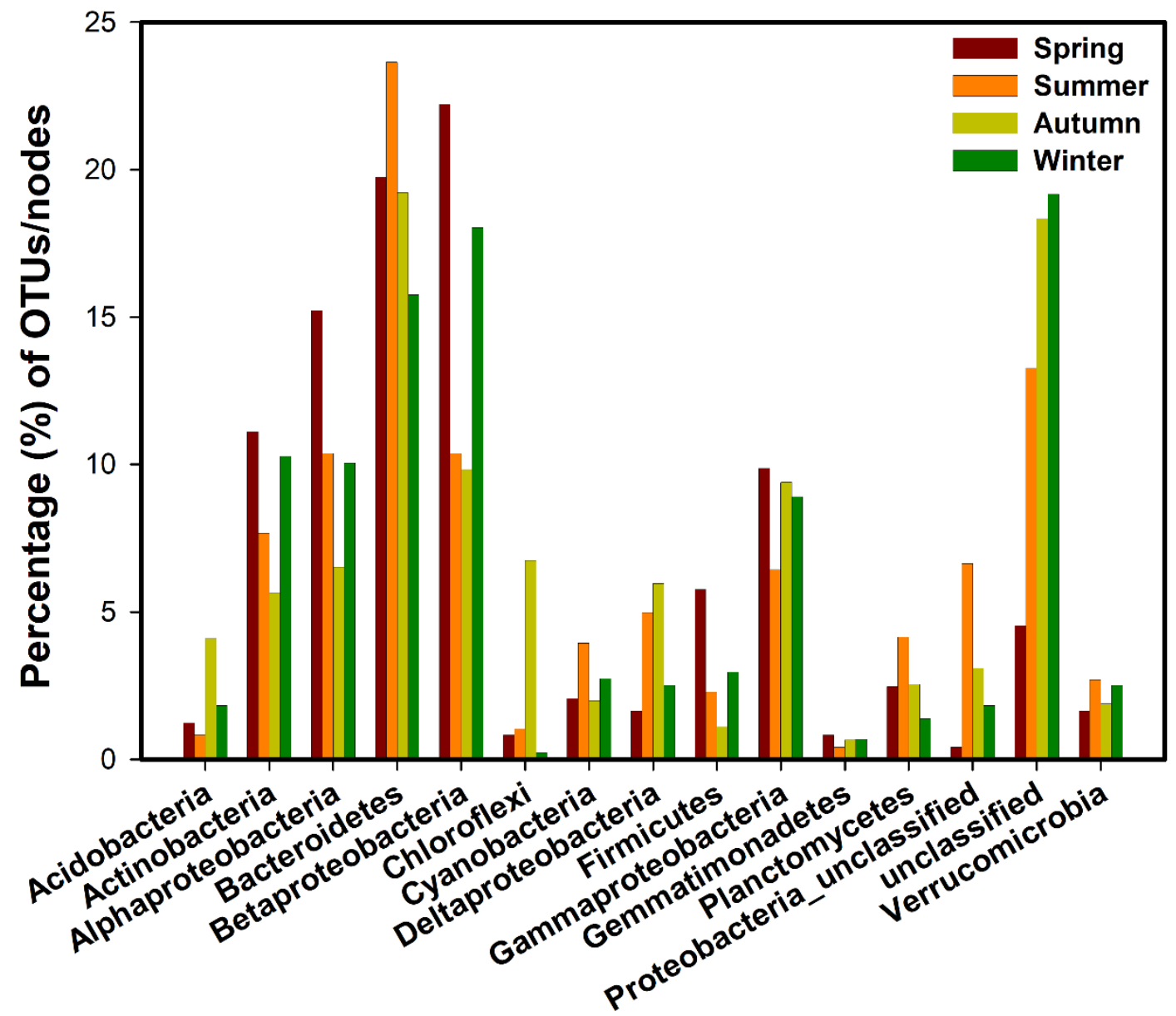

Figure 3. The percentage (\%) of OTUs/nodes in each phylum/subphylum in the four seasonal networks of bacterial communities. Only phyla/classes that appeared in four seasonal species-species association networks are presented.

\subsection{Co-Occurrence/Co-Exclusion Patterns in the Different Seasonal Networks}

The modularity values of the four seasonal networks (spring: 0.931, summer: 0.852 , autumn: 0.739 , winter: 0.851) were all $>0.4$, indicating that all the networks had modular structures. Therefore, we divided the species-species association networks by module to explore the co-occurrence/co-exclusion patterns within the different seasonal bacterial communities. The species-species association networks differed clearly between seasons (Figure 2 and Table S2). All species-species networks contained more positive correlations (positive edges) than negative correlations (negative edges). The autumn network contained the most positive correlations and the highest average degree, followed by the summer and winter networks (Figure 2 and Table 1). We observed the highest modularity value in the spring network, although this network had no negative correlations.

\subsection{Topological Roles of Individual Nodes in Different Seasonal Networks}

The topological roles of the OTUs identified in the four seasonal networks are detailed in Figure 4. Most OTUs (spring: $100 \%$, summer: $98.8 \%$, autumn: $97.5 \%$, winter: $98.4 \%$ ) were peripherals, with the majority of their links inside their modules. Among these peripherals, most $(99.2 \%, 91.1 \%, 79.8 \%$ and $90.4 \%$ for spring, summer, autumn and winter, respectively) had no links to other modules (i.e., $\mathrm{Pi}=0$ ). We found no module hubs and connectors in the spring network and all the seasonal networks lacked network hubs (Figure 4). For the summer network, we observed three module hubs and three connectors (Figure 4). As well, we found 21 module hubs and two connectors in the autumn network, as well as five module hubs and two connectors in the winter network 
(Figure 4). Most of these module hubs and connectors belonged to the five dominant phyla/classes (i.e., Actinobacteria, Alphaproteobacteria, Bacteroidetes, Betaproteobacteria and Gammaproteobacteria; Table 2); we observed some other phyla/classes occurring in relatively low proportion (i.e., Acidobacteria, Chloroflexi, Deltaproteobacteria, and Gemmatimonadetes) or some emerging phyla (i.e., Cloacimonetes and Lentisphaerae) associated to module hubs or connectors. Although Bacteroidetes maintained a relatively higher proportion in summer, module hubs in the summer network were mainly attached to Alphaproteobacteria (denovo3272 and denovo0386) (Table 2). In contrast, some module hubs of autumn and winter networks were affiliated with the phylum Bacteroidetes (autumn: denovo3266, denovo4788, denovo6589, denovo9608 and denovo10588; winter: denovo3884) (Table 2).

(A) Spring

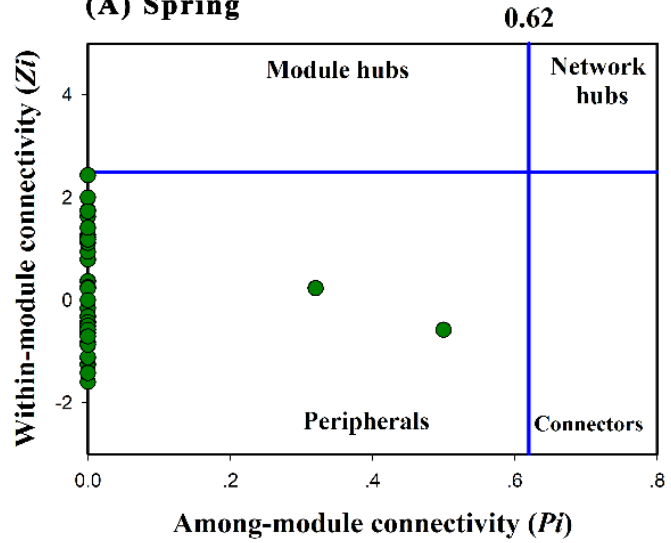

(C) Autumn

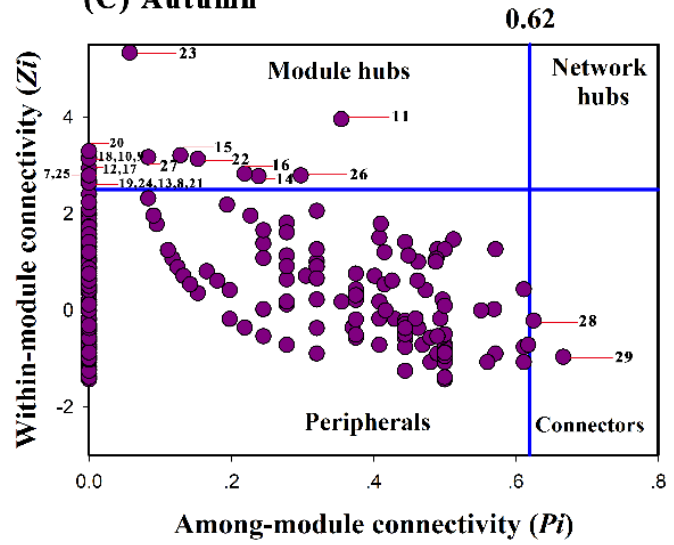

(B) Summer

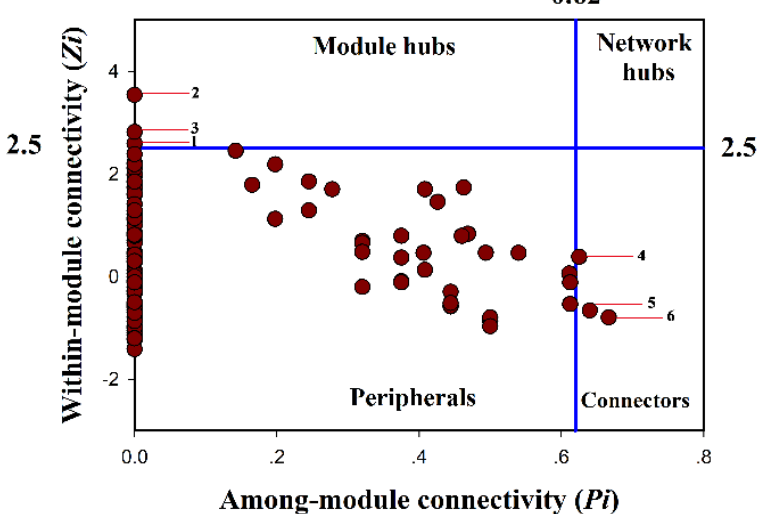

(D) Winter

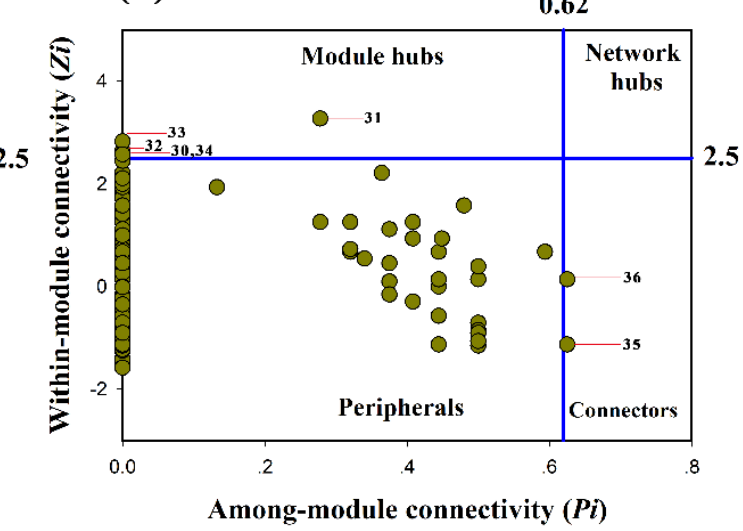

Figure 4. Zi-Pi plot showing the distribution of OTUs based on their topological roles. Each symbol represents an OTU in the spring (A), summer (B), autumn (C) or winter (D) bacterial group. The topological role of each OTU was determined according to the scatterplot of within-module connectivity ( $\mathrm{Zi})$ and among-module connectivity $(\mathrm{Pi})$. 
Table 2. Module hubs and connectors in the species-species association networks. k, p, c, o, f and g represent kingdom, phylum, class, order, family and genus, respectively.

\begin{tabular}{|c|c|c|c|c|c|c|c|}
\hline Season & Type of Point & Number of Node & OTU ID & Number of Module & Mean Abundance (\%) & Phylum/Class & Lowest Taxonomic Rank \\
\hline \multirow{6}{*}{ Summer } & Module hubs & 1 & denovo3272 & B8 & 0.006 & Alphaproteobacteria & g_Sphingorhabdus \\
\hline & & 2 & denovo4293 & B1 & 0.013 & Unclassified & k_Bacteria \\
\hline & & 3 & denovo10386 & B6 & 0.003 & Alphaproteobacteria & f_Sphingomonadaceae \\
\hline & Connectors & 4 & denovo830 & B1 & 0.014 & Chloroflexi & g_Oscillochloris \\
\hline & & 5 & denovo7514 & B2 & 0.095 & Deltaproteobacteria & g_Labilithrix \\
\hline & & 6 & denovo12061 & B3 & 0.030 & Alphaproteobacteria & $f$ _Acetobacteraceae \\
\hline \multirow[t]{21}{*}{ Autumn } & Module hubs & 7 & denovo113 & C9 & 0.002 & Proteobacteria_unclassified & p_Proteobacteria \\
\hline & & 8 & denovo1308 & $\mathrm{C} 24$ & 0.035 & Gammaproteobacteria & o_Chromatiales \\
\hline & & 9 & denovo1615 & $\mathrm{C} 10$ & 0.002 & Lentisphaerae & g_Oligosphaera \\
\hline & & 10 & denovo3226 & C6 & 0.009 & Bacteroidetes & g_fluviicola \\
\hline & & 12 & denovo4788 & $\mathrm{C} 14$ & 0.002 & Bacteroidetes & $p \_\overline{B a c t e r o i d e t e s}$ \\
\hline & & 13 & denovo6589 & $\mathrm{C} 7$ & 0.010 & Bacteroidetes & g_Terrimonas \\
\hline & & 14 & denovo7064 & $\mathrm{C} 23$ & 0.009 & Betaproteobacteria & c__Betaproteobacteria \\
\hline & & 15 & denovo8549 & $\mathrm{C} 29$ & 0.089 & Acidobacteria & o_Gp6 \\
\hline & & 16 & denovo8853 & $\mathrm{C} 8$ & 0.014 & Unclassified & k_Bacteria \\
\hline & & 17 & denovo9608 & $\mathrm{C} 14$ & 0.002 & Bacteroidetes & $p \_\overline{B a c t e r o i d e t e s}$ \\
\hline & & 18 & denovo9867 & C9 & 0.005 & Cloacimonetes & c_Candidatus_Cloacamonas \\
\hline & & 19 & denovo9976 & $\mathrm{C} 13$ & 0.003 & Chloroflexi & $f \_C a l d i l i n e a c e a e$ \\
\hline & & 20 & denovo10529 & $\mathrm{C} 8$ & 0.005 & Unclassified & k__Bacteria \\
\hline & & 21 & denovo10588 & $\mathrm{C} 8$ & 0.017 & Bacteroidetes & $p \_\overline{B a c t e r o i d e t e s}$ \\
\hline & & 22 & denovo10876 & $\mathrm{C} 12$ & 0.005 & Gemmatimonadetes & g_Gemmatimonas \\
\hline & & 24 & denovo11435 & $\mathrm{C} 8$ & 0.003 & Alphaproteobacteria & $f \_$_aulobacteraceae \\
\hline & & 25 & denovo11533 & C9 & 0.002 & Unclassified & k_Bacteria \\
\hline & & 26 & denovo11626 & C11 & 0.006 & Chloroflexi & $f \_$Anaerolineaceae \\
\hline & & 27 & denovo11710 & $\mathrm{C} 23$ & 0.003 & Gammaproteobacteria & c_Gammaproteobacteria \\
\hline & Connectors & 28 & denovo715 & $\mathrm{C} 10$ & 0.009 & Unclassified & k_Bacteria \\
\hline & & 29 & denovo5057 & $\mathrm{C} 3$ & 0.003 & Bacteroidetes & o_Cytophagales \\
\hline \multirow{7}{*}{ Winter } & Module hubs & 30 & denovo95 & D3 & 0.018 & Gammaproteobacteria & c_Gammaproteobacteria \\
\hline & & 31 & denovo2361 & D4 & 0.315 & Betaproteobacteria & $f$ __Methylophilaceae \\
\hline & & 32 & denovo2444 & D16 & 0.004 & Unclassified & k_Bacteria \\
\hline & & 33 & denovo3884 & D15 & 0.003 & Bacteroidetes & f_Chitinophagaceae \\
\hline & & 34 & denovo13572 & D3 & 0.087 & Actinobacteria & o_Actinomycetales \\
\hline & Connectors & 35 & denovo3821 & D24 & 0.623 & Alphaproteobacteria & $f$ _Rhodobacteraceae \\
\hline & & 36 & denovo9640 & D4 & 0.004 & Alphaproteobacteria & g_Caulobacter \\
\hline
\end{tabular}




\subsection{Relationships between Species and Environmental Variables in Different Seasons}

We added the measured environmental variables to the four seasonal networks (solid blue and dotted pink edges represent positive and negative correlations, respectively) to explore the relationships between species interactions and environmental variables within the different seasons (Figure S5). Fewer environmental factors affected summer and spring bacterial groups, particularly in the summer species-environment network, while we observed more correlations between species interactions and environmental variables in the autumn and winter networks (Figure S5). Although many environmental factors appeared in the summer network, only a few environmental factors-DO, $\mathrm{T}$ and Chla-correlated strongly with species. Additionally, the summer network demonstrated a greater number of correlations between different environmental variables. The winter network contained the highest number of significant $(p<0.01)$ correlations ( 40 positive and 71 negative links) (Table S3). Moreover, the spring and autumn networks contained more positive links (38 and 29 for spring and autumn, respectively) than negative links (nine and 12 for spring and autumn, respectively).

\section{Discussion}

\subsection{Interactions among Bacterial Taxa in the Correlation Networks Varied Remarkably between Seasons}

The biodiversity of a bacterial community includes not only the number and abundance of taxa, but also the complex interactions among the various bacteria [41,49]. In the present study, the significant variations observed between the four seasonal networks indicated the markedly variable interactions among bacterial taxa depending on the season (Figure 2). We observed the fewest interactions (edges) in spring and highest number of interactions in the autumn (Table 1). These findings contrast to those of a previous study [12] that found the greatest number of associations in summer and fewest in winter. Seasonal changes in aquacultural activities may explain the unique interactions between bacterial taxa in Eastern Lake Taihu. Generally, juvenile aquacultural species polyculture (i.e., crab, fish and shrimp) only occurs in spring; all adult aquatic products are harvested in autumn. Thus, various forms of water treatment and disinfection are carried out during larviculture (spring). In autumn, however, aquacultural species received a greater amount of food, and there is also increased human activity happen in Eastern Lake Taihu as aquatic products are harvested at this time. Our results observations do match, however, those of by previous studies $[50,51]$ that found that in sites subjected to intense aquacultural activities, fewer intensive bacterial interactions occurred in spring and that these networks became more complex in autumn.

Modularity, an important indicator of network complexity [49], can reflect the diversity of habitat and the clustering of closely related species [52]. We recorded the highest modularity values for the spring bacterial network and the lowest values in autumn (Table 1); therefore, the springtime bacterial community network has more complex correlations within modules, whereas the autumnal bacterial community network has more complex correlations among modules. As such, the autumnal bacterial groups may be more stable than bacterial groups in the other three seasons as a response to environmental change, as indicated by previous results [53]. In addition, the lower average path length and network diameter of the spring bacterial network, possibly due to the network being smallest in the spring, suggested that species were interconnected via very short paths. This pattern could favor the quick and more effective transfer of information (i.e., gives the impression of communication between bacteria) relative to other seasonal networks [54]. In addition, positive correlations dominated all species-species networks (Table 1 and Figure 2). Previous studies have suggested that species tend to have more positive interactions under eutrophic conditions because of reduced competition for nutrients among species sharing similar ecological niches $[12,43,55]$. Thus, given the current eutrophication of Lake Taihu [56,57], the favorable nutrient status for bacterial communities and decreased nutrients could explain the dominance of positive interactions in our study [58]. However, these correlations changed markedly between seasons, and therefore, may also reflect both variable nutrients abundance and changes in the dominant aquaculture activities of the different seasons (Table 3). 
Table 3. Environmental characteristics of water samples collected from Eastern Lake Taihu under aquaculture conditions for each season.

\begin{tabular}{|c|c|c|c|c|c|c|c|c|c|c|c|}
\hline Season & $\mathrm{T}\left({ }^{\circ} \mathrm{C}\right)$ & $\mathrm{pH}$ & DO $(\mathrm{mg} / \mathrm{L})$ & SD (m) & Chla $(\mu \mathrm{g} / \mathrm{L})$ & TN (mg/L) & TP (mg/L) & DOC (mg/L) & $\mathrm{NH}_{4}{ }^{+}-\mathrm{N}(\mathrm{mg} / \mathrm{L})$ & $\mathrm{NO}_{3}{ }^{-}-\mathrm{N}(\mathrm{mg} / \mathrm{L})$ & $\mathrm{NO}_{2}{ }^{-}-\mathrm{N}(\mathrm{mg} / \mathrm{L})$ \\
\hline Spring & $17.19 \pm 0.11$ & $8.84 \pm 0.60$ & $7.57 \pm 0.96$ & $1.26 \pm 0.23$ & $2.30 \pm 2.38$ & $0.80 \pm 0.15$ & $0.072 \pm 0.045$ & $7.35 \pm 0.86$ & $0.074 \pm 0.038$ & $0.165 \pm 0.138$ & $0.010 \pm 0.004$ \\
\hline Summer & $31.60 \pm 1.02$ & $8.23 \pm 0.40$ & $4.02 \pm 1.24$ & $0.38 \pm 0.11$ & $59.05 \pm 26.72$ & $1.25 \pm 0.54$ & $0.127 \pm 0.035$ & $5.52 \pm 1.19$ & $0.021 \pm 0.008$ & $0.279 \pm 0.078$ & $0.003 \pm 0.002$ \\
\hline Autumn & $19.61 \pm 0.13$ & $8.25 \pm 0.25$ & $7.43 \pm 0.59$ & $0.42 \pm 0.10$ & $7.98 \pm 3.25$ & $0.64 \pm 0.07$ & $0.031 \pm 0.005$ & $9.86 \pm 2.28$ & $0.058 \pm 0.019$ & $0.067 \pm 0.029$ & $0.004 \pm 0.002$ \\
\hline Winter & $3.36 \pm 0.36$ & $7.96 \pm 0.11$ & $7.19 \pm 0.79$ & $0.61 \pm 0.34$ & $6.47 \pm 2.01$ & $1.16 \pm 0.22$ & $0.025 \pm 0.006$ & $11.32 \pm 2.84$ & $0.099 \pm 0.026$ & $0.456 \pm 0.142$ & $0.006 \pm 0.004$ \\
\hline
\end{tabular}

$\mathrm{T}$, water temperature; $\mathrm{DO}$, dissolved oxygen; $\mathrm{SD}$, Secchi depth; Chla, chlorophyll a; $\mathrm{TP}$, total phosphorus; $\mathrm{DOC}$, dissolved organic carbon; $\mathrm{TN}$, total nitrogen; $\mathrm{NO}_{3}{ }^{-}-\mathrm{N}_{\text {, nitrate nitrogen; }}$ $\mathrm{NH}_{4}{ }^{-}-\mathrm{N}$, ammonia nitrogen; $\mathrm{NO}_{2}^{-}-\mathrm{N}$, nitrite nitrogen. 


\subsection{Different Topological Roles of Individual OTUs Observed in Bacterial Community Networks}

Individual species (OTUs) have various topological roles in the network [48]. In accordance with previous studies $[40,43,59]$, individual OTUs in our study could be separated into four types of topological nodes in a network. However, most OTUs were peripheral OTUs, having the majority of their links inside their associated modules [41] (Figure 4). Moreover, both connectors and module hubs played vital topological roles in the network and were associated with the modular nature of the network [49]. Our results further revealed that not only topological roles of individual OTUs varied over the seasons, but also modular nature significantly changed across different seasons. These findings were fully supported by previous studies $[12,60]$. In addition, we observed an increase in the number of connectors and module hubs in the autumn network. This pattern indicated that species were more tightly linked in the autumn, thereby maintaining a more stable bacterial network [53]. On the contrary, no module hubs or connectors were found in the spring network. This absence suggests that the spring network could fragment more easily and be more vulnerable to the collapse of the entire network [49]. Meanwhile, the observation of only positive correlations in the spring bacterial communities may also reflect this instability, as previous work has shown that more negative correlations within ecological communities enhance the stability of networks under disturbed conditions [43,49].

Most module hubs and connectors were assigned to the five dominant phyla/classes (i.e., Actinobacteria, Alphaproteobacteria, Bacteroidetes, Betaproteobacteria and Gammaproteobacteria) (Table 2). These bacteria adapt easily to environmental change, as shown by their high relative proportions (Figure 3) [40]. It is worth noting that Alphaproteobacteria are ubiquitous in freshwater lakes and competitive at utilization of nutrients, as well as capable of degrading complex organic compounds $[61,62]$. Therefore, OTUs of this phylum occupied important topological roles in the summer, autumn and winter bacterial networks, possibly due to the eutrophication of the eastern portion of Lake Taihu. Additionally, literatures have recorded that Bacteroidetes showed strong correlations with high concentrations of dissolved organic carbon (DOC) [61,63], which indicated that Bacteroidetes possessed higher activity under high DOC concentrations. Therefore, OTUs assigned to Bacteroidetes were more likely to be positioned as module hubs or connectors in the autumn and winter networks due to the relatively higher DOC concentrations in both of these seasons (Table 3); subsequently, no Bacteroidetes OTUs acted as module hubs or connectors in the summer bacterial network when the lowest DOC concentrations were recorded (Table 3).

\subsection{Relationships between Species and Environmental Variables Varied between Seasons}

The effects of environmental variables on bacterial communities are well known [64-67]; however, relationships between species interactions and environmental variables remain unclear. In Lake Taihu, relationships between species networks and environmental variables dramatically changed between seasons (Figure S5), an observation consistent with previous studies $[8,12,68,69]$. In addition, we observed that fewer environmental variables correlated strongly with bacterial species in the spring than in the other seasons. One of the possible reasons may be attributed to the simpler network in spring.

Our present study was carried out in a shallow and eutrophic lake [4]. This makes it relatively easy to have strong hydrological mixing, especially in the summer when rainfall events are more frequent [70]. Hence, although similar networks were found in summer and winter, the relationships between species interactions and environmental variables varied remarkably in summer and winter. This difference may reflect the more homogeneous environmental conditions in summer related to these more frequent and strong rainfall-related hydrological disturbance in the summer [71]. Moreover, higher concentrations of TN and TP in the summer also weaken environmental filtering [58], thereby decreasing the environmental dependence of species. This lower dependence leads to fewer significant relationships between species interactions and environmental variables in summer. On the contrary, we observed more negative correlations in the species-environment association network in winter, especially for those associations that involved temperature. Lower temperatures in winter reduce the 
growth, maintenance and survival rates of microbes [72]; in turn, the environmental dependence of species increases. Only the seasonal scale was considered in this study, thereby ignoring the effects of aquaculture on interactions among bacterial taxa. Additionally, given that this study was carried out in only one year, a multi-year assessment is valuable to explore the effects of aquaculture activities on bacterial species interactions.

\section{Conclusions}

Here, we demonstrated that network structures and co-occurrence patterns varied remarkably between seasons in a freshwater system subjected to a strong aquacultural influence (Eastern Lake Taihu, China). We observed stronger and more complex interactions in the autumn network and a simpler bacterial network in the spring. The topological roles of individual OTUs changed over the seasons, although the dominant phyla/classes maintained key roles in different seasons. We also revealed that the relationships between species and environmental variables changed markedly over the seasons. Fewer environmental factors were correlated with bacterial species in spring, while we observed fewer correlations in the summer species-environment association network and a greater number of relationships between species and environmental factors in winter. Our findings highlight the effects of seasonality on bacterial community interactions and provide a basis for a more comprehensive understanding of the effects of aquacultural activities on freshwater ecosystems.

Supplementary Materials: The following are available online at http://www.mdpi.com/2073-4441/11/9/1868/s1, Figure S1: Diversity (A) and richness (B) of the bacterial communities across seasons. Different letters above columns show the remarkable differences based on one-way ANOVA with Duncan's comparisons $(p<0.05)$. Figure S2: Non-metric multidimensional scaling analysis (NMDS) of bacterial community composition for each season (A) and each zone (B) based on the weighted UniFrac distance. Difference was tested based on 999 permutations using 'anosim' functions in R. Figure S3: The OTU connectivity distributions of bacterial community networks in different seasons as fitted by power-law, exponential-law and truncated power-law models (A, spring; B, summer; C, autumn; D, winter). The $\mathrm{x}$-axis is the node connectivity. The y-axis is the number of nodes under a given connectivity. The values on both axes are log-transformed. Rsqr values represent the degree of the fitting models (undetermined fitting value found are shown by 'Error'). Figure S4: The relative abundance of dominant bacterial phyla/classes for each season. Phyla/classes with a relative abundance of $>0.5 \%$ are presented, whereas those with relative abundance $<0.5 \%$ were included in the 'others' group. The height of each bar denotes the average relative abundance of each phylum. Asterisks above bars represent significant differences from the Kruskal-Wallis $H$-test. ${ }^{*} p<0.05 ;{ }^{* *} p<0.01 ;{ }^{* * *} p<0.001$. Figure S5: Species-environment network of bacterial communities in spring (A), summer (B), autumn (C) and winter (D). Only correlations between species that were statistically significant $(p<0.001)$ and strong $(r>0.9$ or $r<-0.9)$ are shown by solid blue lines (positive correlations) and dotted pink lines (negative correlations), respectively. Only correlations between environmental factors and species interactions that were significant $(p<0.01)$ are shown. Correlations between pairs of OTUs and OTUs uncorrelated to any environmental variables are not shown. Different bacterial phyla/classes are represented by different colors, and the number on each node represents the ID number of each OTU. T, water temperature; DO, dissolved oxygen; SD, Secchi depth; Chla, chlorophyll $a$; TN, total nitrogen; TP, total phosphorus; DOC, dissolved organic carbon. Table S1: The percentage (\%) of OTUs/nodes in the bacterial networks assigned to each phylum/subphylum for each season. Table S2: The top 10 correlations of the species-species association network in the present study. Table S3: The number of positive/negative links between environmental variables and species interactions in species-environment association network of the different seasons.

Author Contributions: Conceptualization, D.Z. and Y.L.; Methodology, X.C. and C.J.; Software, X.C. and Y.L.; Validation, Y.L., D.Z. and J.Z.; Formal Analysis, C.J. and Y.L.; Investigation, C.J. and Y.L.; Writing-Original Draft Preparation, Y.L.; Writing-Review and Editing, D.Z. and J.Z.; Supervision, D.Z.; Funding Acquisition, D.Z. and J.Z.

Funding: This research was funded by the National Key R\&D Program of China (2016YFC0402710), the National Natural Science Foundation of China (31730013, 41621002, 41571108, 41671078 and 41871096), the National Key Technology R\&D Program (2015BAD13B01), the Key Research Program of Frontier Science, CAS (QYZDJ-SSW-DQC030), the Natural Science Foundation of Jiangsu Province (BK20181311), the Fundamental Research Funds for the Central Universities (2018B43414) and the Belt and Road Special Foundation of the State Key Laboratory of Hydrology-Water Resources and Hydraulic Engineering (2018490211).

Acknowledgments: We thank Huiming $\mathrm{Xu}$ and Xiaowei He for sample collection and water filtration.

Conflicts of Interest: The authors declare no conflict of interest. 


\section{References}

1. FAO. The State of World Fisheries and Aquaculture 2018-Meeting the Sustainable Development Goals. 2018. Available online: http://www.fao.org/3/i9540en/I9540EN.pdf (accessed on 12 July 2018).

2. Cai, C.; Gu, X.; Ye, Y.; Yang, C.; Dai, X.; Chen, D.; Yang, C. Assessment of pollutant loads discharged from aquaculture ponds around Taihu Lake, China. Aquac. Res. 2013, 44, 795-806. [CrossRef]

3. Fang, Y.; Li, H.; He, H. Dynamic Monitoring of Lake Reclamation in the Taihu Lake and Lake Enclosure Culture of the East Taihu Lake in Recent 30 Years. Resour. Environ. Yangtze Basin 2012, 21, 121-126.

4. Qin, B.; Xu, P.; Wu, Q.; Luo, L.; Zhang, Y. Environmental issues of lake Taihu, China. In Eutrophication of Shallow Lakes with Special Reference to Lake Taihu, China; Springer: Berlin/Heidelberg, Germany, 2007; pp. 3-14.

5. Wu, Y.; Xiang, Y.; Wang, J.; Zhong, J.; He, J.-Z.; Wu, Q.L. Heterogeneity of archaeal and bacterial ammonia-oxidizing communities in Lake Taihu, China. Environ. Microbiol. Rep. 2010, 2, 569-576. [CrossRef] [PubMed]

6. Yin, Q.; Yue, D.; Peng, Y.; Liu, Y.; Xiao, L. Occurrence and Distribution of Antibiotic-resistant Bacteria and Transfer of Resistance Genes in Lake Taihu. Microbes Environ. 2013, 28, 479-486. [CrossRef]

7. Grossart, H.-P.; Ploug, H. Microbial degradation of organic carbon and nitrogen on diatom aggregates. Limnol. Oceanogr. 2001, 46, 267-277. [CrossRef]

8. Jiao, N.; Herndl, G.J.; Hansell, D.A.; Benner, R.; Kattner, G.; Wilhelm, S.W.; Kirchman, D.L.; Weinbauer, M.G.; Luo, T.; Chen, F.; et al. Microbial production of recalcitrant dissolved organic matter: Long-term carbon storage in the global ocean. Nat. Rev. Genet. 2010, 8, 593-599. [CrossRef] [PubMed]

9. Weiss, S.; Van Treuren, W.; Lozupone, C.; Faust, K.; Friedman, J.; Deng, Y.; Xia, L.C.; Xu, Z.Z.; Ursell, L.; Alm, E.J.; et al. Correlation detection strategies in microbial data sets vary widely in sensitivity and precision. ISME J. 2016, 10, 1669-1681. [CrossRef]

10. Gilbert, J.A.; Field, D.; Swift, P.; Newbold, L.; Oliver, A.; Smyth, T.; Somerfield, P.J.; Huse, S.; Joint, I. The seasonal structure of microbial communities in the Western English Channel. Environ. Microbiol. 2009, 11, 3132-3139. [CrossRef]

11. Gilbert, J.A.; Steele, J.A.; Caporaso, J.G.; Steinbrück, L.; Reeder, J.; Temperton, B.; Huse, S.; McHardy, A.C.; Knight, R.; Joint, I. Defining seasonal marine microbial community dynamics. ISME J. 2012, 6, 298-308. [CrossRef]

12. Zhao, D.; Shen, F.; Zeng, J.; Huang, R.; Yu, Z.; Wu, Q.L. Network analysis reveals seasonal variation of co-occurrence correlations between Cyanobacteria and other bacterioplankton. Sci. Total Environ. 2016, 573, 817-825. [CrossRef]

13. Nelson, C.E. Phenology of high-elevation pelagic bacteria: The roles of meteorologic variability, catchment inputs and thermal stratification in structuring communities. ISME J. 2009, 3, 13-30. [CrossRef] [PubMed]

14. Zhao, D.; Cao, X.; Huang, R.; Zeng, J.; Xu, H.; Wang, S.; He, X.; Yu, Z.; Shen, F. The heterogeneity of composition and assembly processes of the microbial community between different nutrient loading lake zones in Taihu Lake. Appl. Microbiol. Biotechnol. 2017, 101, 5913-5923. [CrossRef] [PubMed]

15. Jones, A.C.; Hambright, K.D.; Caron, D.A. Ecological patterns among bacteria and microbial eukaryotes derived from network analyses in a low-salinity lake. Microbial Ecol. 2018, 75, 917-929. [CrossRef] [PubMed]

16. Kandel, P.P.; Pasternak, Z.; Nahum, O.; Van Rijn, J.; Jurkevitch, E. Abundance, diversity and seasonal dynamics of predatory bacteria in aquaculture zero discharge systems. FEMS Microbiol. Ecol. 2014, 89, 149-161. [CrossRef] [PubMed]

17. Wang, L.; Li, T. Effects of seasonal temperature variation on nitrification, anammox process, and bacteria involved in a pilot-scale constructed wetland. Environ. Sci. Pollut. R. 2015, 22, 3774-3783. [CrossRef] [PubMed]

18. Denef, V.J.; Fujimoto, M.; Berry, M.A.; Schmidt, M.L. Seasonal Succession Leads to Habitat-Dependent Differentiation in Ribosomal RNA:DNA Ratios among Freshwater Lake Bacteria. Front. Microbiol. 2016, 7, 32. [CrossRef]

19. Giovannoni, S.J.; Vergin, K.L. Seasonality in Ocean Microbial Communities. Science 2012, 335, 671-676. [CrossRef]

20. Williams, R.J.; Howe, A.; Hofmockel, K.S. Demonstrating microbial co-occurrence pattern analyses within and between ecosystems. Front. Microbiol. 2014, 5, 358. [CrossRef] 
21. Ings, T.C.; Montoya, J.M.; Bascompte, J.; Blüthgen, N.; Brown, L.; Dormann, C.F.; Edwards, F.; Figueroa, D.; Jacob, U.; Jones, J.I. Ecological networks-beyond food webs. J. Anim. Ecol. 2009, 78, 253-269. [CrossRef]

22. Poulin, R. Network analysis shining light on parasite ecology and diversity. Trends Parasitol. 2010, 26, 492-498. [CrossRef]

23. Proulx, S.; Promislow, D.; Phillips, P. Network thinking in ecology and evolution. Trends Ecol. Evol. 2005, 20, 345-353. [CrossRef] [PubMed]

24. Bascompte, J. Networks in ecology. Basic Appl. Ecol. 2007, 8, 485-490. [CrossRef]

25. Montoya, J.M.; Pimm, S.L.; Solé, R.V. Ecological networks and their fragility. Nature 2006, 442, $259-264$. [CrossRef] [PubMed]

26. Zeng, J.; Lin, Y.; Zhao, D.; Huang, R.; Xu, H.; Jiao, C. Seasonality overwhelms aquacultural activity in determining the composition and assembly of the bacterial community in Lake Taihu, China. Sci. Total Environ. 2019, 683, 427-435. [CrossRef] [PubMed]

27. Caporaso, J.G.; Kuczynski, J.; Stombaugh, J.; Bittinger, K.; Bushman, F.D.; Costello, E.K.; Fierer, N.; Peña, A.G.; Goodrich, J.K.; Gordon, J.I.; et al. QIIME allows analysis of high-throughput community sequencing data. Nat. Methods 2010, 7, 335-336. [CrossRef] [PubMed]

28. Bolger, A.M.; Lohse, M.; Usadel, B. Trimmomatic: A flexible trimmer for Illumina sequence data. Bioinformatics 2014, 30, 2114-2120. [CrossRef] [PubMed]

29. Magoč, T.; Salzberg, S.L. FLASH: Fast length adjustment of short reads to improve genome assemblies. Bioinformatics 2011, 27, 2957-2963. [CrossRef]

30. Edgar, R.C.; Haas, B.J.; Clemente, J.C.; Quince, C.; Knight, R. UCHIME improves sensitivity and speed of chimera detection. Bioinformatics 2011, 27, 2194-2200. [CrossRef]

31. Edgar, R.C. Search and clustering orders of magnitude faster than BLAST. Bioinformatics 2010, 26, $2460-2461$. [CrossRef]

32. Rognes, T.; Flouri, T.; Nichols, B.; Quince, C.; Mahé, F. VSEARCH: A versatile open source tool for metagenomics. PeerJ 2016, 4, e2584. [CrossRef]

33. Zhao, D.; Xu, H.; Zeng, J.; Cao, X.; Huang, R.; Shen, F.; Yu, Z. Community composition and assembly processes of the free-living and particle-attached bacteria in Taihu Lake. FEMS Microbiol. Ecol. 2017, 93, fix062. [CrossRef] [PubMed]

34. Wang, Q.; Garrity, G.M.; Tiedje, J.M.; Cole, J.R. Naïve Bayesian Classifier for Rapid Assignment of rRNA Sequences into the New Bacterial Taxonomy. Appl. Environ. Microbiol. 2007, 73, 5261-5267. [CrossRef] [PubMed]

35. Caporaso, J.G.; Bittinger, K.; Bushman, F.D.; DeSantis, T.Z.; Andersen, G.L.; Knight, R. PyNAST: A flexible tool for aligning sequences to a template alignment. Bioinformatics 2010, 26, 266-267. [CrossRef] [PubMed]

36. Quast, C.; Pruesse, E.; Yilmaz, P.; Gerken, J.; Schweer, T.; Yarza, P.; Peplies, J.; Glöckner, F.O. The SILVA ribosomal RNA gene database project: Improved data processing and web-based tools. Nucleic Acids Res. 2012, 41, D590-D596. [CrossRef] [PubMed]

37. Price, M.N.; Dehal, P.S.; Arkin, A.P. FastTree 2-Approximately Maximum-Likelihood Trees for Large Alignments. PLoS ONE 2010, 5, e9490. [CrossRef] [PubMed]

38. Bokulich, N.A.; Subramanian, S.; Faith, J.J.; Gevers, D.; Gordon, J.I.; Knight, R.; Mills, D.A.; Caporaso, J.G. Quality-filtering vastly improves diversity estimates from Illumina amplicon sequencing. Nat. Methods 2013, 10, 57-59. [CrossRef] [PubMed]

39. Xu, H.; Zhao, D.; Huang, R.; Cao, X.; Zeng, J.; Yu, Z.; Hooker, K.V.; Hambright, K.D.; Wu, Q.L. Contrasting Network Features between Free-Living and Particle-Attached Bacterial Communities in Taihu Lake. Microb. Ecol. 2018, 76, 303-313. [CrossRef]

40. Zhou, J.; Deng, Y.; Luo, F.; He, Z.; Yang, Y. Phylogenetic Molecular Ecological Network of Soil Microbial Communities in Response to Elevated CO2. mBio 2011, 2, e00122-11. [CrossRef]

41. Harrell, F.E., Jr.; Dupont, C. Hmisc: Harrell Miscellaneous. R Package Version. 2008. Available online: http://ftp.auckland.ac.nz/software/CRAN/contrib/main/Descriptions/Hmisc.html (accessed on 7 September 2019).

42. Cao, X.; Zhao, D.; Xu, H.; Huang, R.; Zeng, J.; Yu, Z. Heterogeneity of interactions of microbial communities in regions of Taihu Lake with different nutrient loadings: A network analysis. Sci. Rep. 2018, 8, 8890. [CrossRef]

43. Junker, B.H.; Schreiber, F. Analysis of Biological Networks; Wiley-Interscience: Hoboken, NJ, USA, 2008; Volume 2, pp. 31-59. 
44. Shannon, P.; Markiel, A.; Ozier, O.; Baliga, N.S.; Wang, J.T.; Ramage, D.; Amin, N.; Schwikowski, B.; Ideker, T. Cytoscape: a software environment for integrated models of biomolecular interaction networks. Genome Res. 2003, 13, 2498-2504. [CrossRef]

45. Su, G.; Morris, J.H.; Demchak, B.; Bader, G.D. Biological Network Exploration with Cytoscape 3. Curr. Protoc. Bioinform. 2014, 47, 8.13.1-8.13.24. [CrossRef] [PubMed]

46. Clauset, A.; Newman, M.E.J.; Moore, C. Finding community structure in very large networks. Phys. Rev. E 2004, 70, 066111. [CrossRef] [PubMed]

47. Csardi, G.; Nepusz, T. The igraph software package for complex network research. InterJ. Complex Syst. 2006, 1695, 1-9.

48. Guimerà, R.; Amaral, L.A.N. Functional cartography of complex metabolic networks. Nature 2005, 433, 895-900. [CrossRef] [PubMed]

49. Olesen, J.M.; Bascompte, J.; Dupont, Y.L.; Jordano, P. The modularity of pollination networks. Proc. Natl. Acad. Sci. USA 2007, 104, 19891-19896. [CrossRef]

50. Olafsen, J.A. Interactions between fish larvae and bacteria in marine aquaculture. Aquaculture 2001, 200, 223-247. [CrossRef]

51. Blancheton, J.; Attramadal, K.; Michaud, L.; D'Orbcastel, E.R.; Vadstein, O. Insight into bacterial population in aquaculture systems and its implication. Aquac. Eng. 2013, 53, 30-39. [CrossRef]

52. Lewinsohn, T.M.; Prado, P.I.; Jordano, P.; Bascompte, J.; Olesen, J.M. Structure in plant-animal interaction assemblages. Oikos 2006, 113, 174-184. [CrossRef]

53. Mougi, A.; Kondoh, M.; Hurtgen, M.T. Diversity of Interaction Types and Ecological Community Stability. Science 2012, 337, 349-351. [CrossRef]

54. Zou, L.; Pei, W.; Li, T.; He, Z.; Cheung, Y. Topological fractal networks introduced by mixed degree distribution. Phys. A Stat. Mech. Its Appl. 2007, 380, 592-600. [CrossRef]

55. May, R.; McLean, A.R. Theoretical Ecology: Principles and Applications; Oxford University Press on Demand: Oxford, UK, 2007.

56. Tang, X.; Chao, J.; Gong, Y.; Wang, Y.; Wilhelm, S.W.; Gao, G. Spatiotemporal dynamics of bacterial community composition in large shallow eutrophic Lake Taihu: High overlap between free-living and particle-attached assemblages. Limnol. Oceanogr. 2017, 62, 1366-1382. [CrossRef]

57. Paerl, H.W.; Xu, H.; Hall, N.S.; Rossignol, K.L.; Joyner, A.R.; Zhu, G.; Qin, B. Nutrient limitation dynamics examined on a multi-annual scale in Lake Taihu, China: Implications for controlling eutrophication and harmful algal blooms. J. Freshw. Ecol. 2015, 30, 5-24. [CrossRef]

58. Zhou, J.; Deng, Y.; Zhang, P.; Xue, K.; Liang, Y.; Van Nostrand, J.D.; Yang, Y.; He, Z.; Wu, L.; Stahl, D.A.; et al. Stochasticity, succession, and environmental perturbations in a fluidic ecosystem. Proc. Natl. Acad. Sci. USA 2014, 111, E836-E845. [CrossRef] [PubMed]

59. Wu, L.; Yang, Y.; Chen, S.; Zhao, M.; Zhu, Z.; Yang, S.; Qu, Y.; Ma, Q.; He, Z.; Zhou, J.; et al. Long-term successional dynamics of microbial association networks in anaerobic digestion processes. Water Res. 2016, 104, 1-10. [CrossRef] [PubMed]

60. Eiler, A.; Heinrich, F.; Bertilsson, S. Coherent dynamics and association networks among lake bacterioplankton taxa. ISME J. 2012, 6, 330-342. [CrossRef]

61. Newton, R.J.; Jones, S.E.; Eiler, A.; McMahon, K.D.; Bertilsson, S. A Guide to the Natural History of Freshwater Lake Bacteria. Microbiol. Mol. Boil. Rev. 2011, 75, 14-49. [CrossRef] [PubMed]

62. Williams, K.P.; Sobral, B.W.; Dickerman, A.W. A Robust Species Tree for the Alphaproteobacteria. J. Bacteriol. 2007, 189, 4578-4586. [CrossRef]

63. Eiler, A.; Bertilsson, S. Flavobacteria Blooms in Four Eutrophic Lakes: Linking Population Dynamics of Freshwater Bacterioplankton to Resource Availability. Appl. Environ. Microbiol. 2007, 73, 3511-3518. [CrossRef]

64. Yannarell, A.C.; Triplett, E.W. Geographic and Environmental Sources of Variation in Lake Bacterial Community Composition. Appl. Environ. Microbiol. 2005, 71, 227-239. [CrossRef]

65. Lindström, E.S.; Langenheder, S. Local and regional factors influencing bacterial community assembly. Environ. Microbiol. Rep. 2012, 4, 1-9. [CrossRef]

66. Beisner, B.E.; Peres-Neto, P.R.; Lindström, E.S.; Barnett, A.; Longhi, M.L. The Role of Environmental and Spatial Processes in Structuring Lake Communities from Bacteria to Fish. Ecology 2006, 87, 2985-2991. [CrossRef] 
67. Cottenie, K. Integrating environmental and spatial processes in ecological community dynamics. Ecol. Lett. 2005, 8, 1175-1182. [CrossRef] [PubMed]

68. Kara, E.L.; Hanson, P.C.; Hu, Y.H.; Winslow, L.; McMahon, K.D. A decade of seasonal dynamics and co-occurrences within freshwater bacterioplankton communities from eutrophic Lake Mendota, WI, USA. ISME J. 2013, 7, 680-684. [CrossRef] [PubMed]

69. Bowers, R.M.; McCubbin, I.B.; Hallar, A.G.; Fierer, N. Seasonal variability in airborne bacterial communities at a high-elevation site. Atmos. Environ. 2012, 50, 41-49. [CrossRef]

70. Zhu, W.; Tan, Y.; Wang, R.; Feng, G.; Chen, H.; Liu, Y.; Li, M. The trend of water quality variation and analysis in typical area of Lake Taihu, 2010-2017. J. Lake Sci. 2018, 30, 296-305.

71. Zhu, C.; Zhang, J.; Nawaz, M.Z.; Mahboob, S.; Al-Ghanim, K.A.; Khan, I.A.; Lu, Z.; Chen, T. Seasonal succession and spatial distribution of bacterial community structure in a eutrophic freshwater Lake, Lake Taihu. Sci. Total Environ. 2019, 669, 29-40. [CrossRef] [PubMed]

72. Price, P.B.; Sowers, T. Temperature dependence of metabolic rates for microbial growth, maintenance, and survival. Proc. Natl. Acad. Sci. USA 2004, 101, 4631-4636. [CrossRef]

(C) 2019 by the authors. Licensee MDPI, Basel, Switzerland. This article is an open access article distributed under the terms and conditions of the Creative Commons Attribution (CC BY) license (http://creativecommons.org/licenses/by/4.0/). 